\title{
6 Types of Communities and Speakers in Language Revitalization
}

\section{José Antonio Flores Farfán and Justyna Olko}

In this chapter, we look at diverse communities who struggle to preserve their heritage languages or who might be interested in launching revitalization programs. We reflect on what it can mean to be a minority or endangered language community and how we can characterize different types of communities. We also look at the implications and challenges for language revitalization that should be considered when taking into account distinct types of communities. The concept of 'community' requires some clarification. As a starting point for this discussion, the community, for the purposes of language revitalization, can be considered any original or newly formed group or network of individuals. These individuals may live in a specific place or may be geographically dispersed, but they are linked by various kinds of interactions and relationships (including those based on both face-to-face and virtual social networks), and share some aspects of their identities and goals. Each community is inherently heterogeneous, variable, highly dynamic, subject to change, and sensitive to all kinds of different factors and circumstances. Communities are usually comprised of distinct groups of speakers, and are maintained or reproduced by different interaction networks.

We have to point out that the 'concept' of revitalization is also blurry and by no means well defined in the literature. Let us just stress that revitalization, as well as several other similar metaphors derived from the biological sciences, have been loosely applied to a wide range of situations, which often differ significantly. They vary from scenarios where only a few speakers prevail with a very limited use of the language (e.g. the Peninsula of Baja California, Mexico, where, for example, Kiliwa has some five speakers left), to communities with about a million speakers and a still pretty robust use of their language and future viability (e.g. Yucatec Maya in the Yucatec Peninsula, Mexico). Some languages are spoken in large communities, some in very small or dispersed ones. Some are still used in relatively isolated areas, while some are used in urban zones where they are exposed to intense contact with other languages. Some languages are valued and recognized, others are associated with trauma, shame, or 
poverty. In dealing with different communities we must be sensitive, flexible, and open to discussion and deep reevaluation of related attitudes in order to start any revitalization project. A strict definition of revitalization is less important than finding effective ways to recover the use of an endangered language in a specific community.

'Revitalizing' a whole community is a fiction or a utopia. Linguistic and cultural revitalization is usually developed by specific groups or individuals from a community, who take the lead in 'reviving' the language. Such activists are motivated by a range of diverse language ideologies, which may, at times, be contradictory and conflicting. For example, plans for revitalization may be met with opposition, indifference, skepticism, or, on the contrary, overenthusiasm, depending on distinct stakeholders.

In order to provide a general typology of such highly heterogeneous language revitalization communities, we will first attempt to provide an overview of their complexity. The field of language revitalization is directly linked to the process of language endangerment and language communities, each with distinct types of 'speakers'. Endangerment refers to a continuum of language use in a specific tongue; the threat of extinction is always a matter of degree. Endangerment is, in fact, faced by most of the languages of the world, which is extremely telling of modern social and political conditions of multilingualism and globalization. Current estimations of the number of tongues spoken vary between roughly six and eight thousand, the majority of which survive in different states of at least some sort of precariousness. They range from 'dormant' languages with very few, if any, speakers, to those with some levels of vitality, most of which comprise communities with a couple of thousand or hundred speakers or even fewer. 'Stable' languages are usually national languages, protected by law, institutions, and other forms of infrastructure as provided by a specific state or political organization. It is estimated that they constitute only some 30 percent of the world's linguistic diversity. Estimates regarding the number of languages still spoken in the world are based on a number of criteria, many of them being imprecise, ideological, and/or political; deciding on where a language or a 'dialect' begins often stems from political and ideological notions. For instance, within the Maya family, Yucatec Maya, Mopan, and Itzá are considered separate languages, mainly because the speakers of the first group dwell in Mexico, whereas the other two reside in Guatemala. In Scandinavia, Norwegian, Swedish, and Danish are recognized as distinct languages, spoken in three different countries, yet linguistically they form a 'dialect continuum' of regional variants that are mutually intelligible to differing degrees. Another interesting and less known example is the Wymysiöeryś language in Poland, which faces obstacles to achieving official recognition, since the basic criterion in the law is that a regional 
language cannot be a 'dialect' of any other national language. The argument employed against the recognition of Wymysiöeryś is its alleged status as a 'dialect' of German, despite a unique historical trajectory, linguistic features, and a low degree (or even lack) of intelligibility with German.

The causes of endangerment encompass a broad range of factors, including the historical consequences of colonialism, genocide, the slave trade, and exploitation, accompanied by discrimination, racism, political domination, economic disadvantages, etc. Postcolonial heritage and the effects of globalization have resulted in a global crisis for languages, the worst that the world has ever experienced. Its effects can be compared to 'the great dying' of species in the remote past as well as to modern processes of accelerated reduction in global biodiversity. Nonetheless these global trends also provoke grassroot responses from local communities. Such responses provide an especially important starting point for any revitalization project.

However, revitalization efforts should consider the specific conditions and situation of the group or 'community' in question. These conditions include not only the degree of language endangerment, but also the motivations, ideologies, goals, aims, desired benefits, and internal politics of its members. Thus awareness of the diversity of communities and linguistic situations needs to be considered while planning and undertaking any (re)vitalization strategy. We must emphasize that there is considerable overlap between distinct types of communities and their speakers: any typology should be considered a continuum or even a kaleidoscope of continua. In the following sections, we describe certain general features and characteristics that many communities share. However we should not forget that the complexity and combination of factors that affect each group, in fact, make each community unique.

\section{'Original' or Ancestral Communities with Different Forms of Language Transmission}

Groups that continue to live in traditional lands and territories and were established in a more or less remote past can be considered 'ancestral communities'. In the present time of linguistic unification, most communities that use their own heritage tongue or language variant that is different from a national or dominant language face the threat of language loss. They may have different degrees of language transmission as well as different forms of language socialization. Many of them suffer displacement and linguistic conflicts, that is, an ideological, functional, and political struggle between the use of the local tongue and the imposed, dominant language. In some of these communities the ancestral language is still spoken, but younger generations have lost interest and proficiency; the natural transmission of the 
language is weakened or broken. Skills in the heritage tongue vary considerably; there are groups of speakers who have become monolingual in a hegemonic national language after passing through a stage of substitutive or replacive bilingualism. This may, for example, be the result of school trauma, especially in residential schools where students were forced to leave their communities and home territories, and abandon the tongue that they learnt at home, as in Australia, Canada, or the USA. Imagine literally having your mouth washed out with soap or standing in the burning sun as a punishment for speaking your language. Unbelievably these practices still occur in some countries. Latin and North America are particularly good examples of the impact that school policies have on language. Across these continents boarding schools and, more recently, 'bilingual schools', have become efficient tools for eradicating Indigenous languages. Similar practices have occurred in other parts of the world, especially in postcolonial contexts or countries that adopted strong nationalistic policies aimed at cultural and linguistic unification of their citizens (Russia, postwar Poland, China, Japan, etc.). In addition, pressures on shifting communities are often linked to economic motivations, including the linguistic requirements of the job market and individuals' desire for social advancement. Typically parents will also be pressured not to pass the heritage language to new generations.

Yet there are interesting cases of resistance to language displacement, including the vital use of an endangered language in settings such as religious rituals, the market place, and other public domains. These kinds of situations are fertile ground for the particular types of (re)vitalization projects that we describe here as 'communities of learning or practice' (see later). Moreover there are also emblematic cases of language recovery and resilience, as in Euskara ('Basque') and Catalan, which were forbidden in Spain in the era of the Franco dictatorship (from the late 1930s until the mid-1970s). Both are now coofficial languages in their respective autonomous regions, yet they still face serious threats and challenges.

Māori, spoken in New Zealand, is another interesting case, with its famous 'language nests' - a methodology consisting of speaking the ancestral language almost from the womb. Even though Māori's vitality is now a fact, with official recognition, support, and institutional use, this does not mean that it is no longer endangered. This is telling of the difficulties in stabilizing a threatened language; despite its relatively successful revitalization, the Māori language is not free from constant challenges and conflicts, even from within the community. For instance, the vitality of Northern Māori varieties is much higher than that of the Southern ones, known as Käi Tahu, which are in an advanced state of shift. The Māori community has been trying to recover Käi Tahu for over two decades, dreaming to replenish the South with Māori and reversing language shift. 
Yet one of the main problems is the conflict between the so-called obsolescent Southern Māori varieties and the vital Northern ones. ${ }^{1}$ This can be seen in the fact that some Northern speakers even mock Southern varieties. This intolerance can happen within language communities, but also in mainstream society. In our work with Indigenous communities we have come across lay people, and even anthropologists, who value certain varieties more than others. These are often varieties that exhibit influence from the dominant language and are viewed as 'impoverished' or 'inauthentic', etc.

Thus, in 'ancestral communities' we often find complex situations when it comes to language maintenance and shift, a continuum with clear internal differences within the same language. Many subvarieties can be associated, for instance, with different generations, as is the case of several Indo-American languages. These range from 'monolingual' or traditional varieties, to highly innovative varieties that may borrow heavily from the dominant language. Such differentiation within the larger language group, as it occurs in specific communities, depends on various factors, including the status of the heritage language, the territory where it is spoken, contact with other languages, the role of migration and the nation states' language policies, etc. Other key factors include the specific ideologies, motivations, attitudes, and goals of speakers. It is important to emphasize that in the same region there may be distinct types of situations of language retention and shift, ranging from conservative groups of speakers of monolingual varieties (e.g. the elders), passing through high levels of bilingualism (e.g. younger generations), to groups within the same community who now use the hegemonic or national language as their first tongue (e.g. children). In the same geographic area, we can also find ancestral communities that have already lost their heritage language entirely or in part.

Often strong traces of the 'lost' language are left in the so-called interlanguage. In this scenario, speakers have not completely acquired the colonial or national tongue, but rather developed a version of the dominant language. Examples include Indo-American Spanish or First Nation peoples' English, which exhibit strong (lexical, phonetic, and structural) influences from the Indigenous languages that were previously or are still spoken in the area. Such scenarios are abundant in almost all parts of the world. In the case of ancestral communities whose traditional tongue has been reduced to an emblem, for symbolic use only, or who have lost the

${ }^{1}$ See H. O'Regan, 'A language to call my own', in A. M. Goodfellow (ed.), Speaking of Endangered Languages (Cambridge: Cambridge Scholars, 2009), pp. 184-98. 
tongue entirely, revitalization efforts must be oriented toward awakening a 'sleeping' language, which had not been spoken for a while and is thus 'dormant'. In these cases, the few last speakers often belong to the eldest generation. One example of awakening a sleeping language is the revitalization of Manx on the Isle of Man, which was brought back to use only after the death of the last speaker, Ned Maddrell - a poet who lived in the isolated village of Cregneash on the island - in 1974. This case shows that the commitment of a group of activists can change the fate of a language, at least in the short- or mid-term.

Even today ancestral communities are typically under intense pressure from dominant languages as well as discriminatory or racist language ideologies (see also Chapter 7). The latter usually come from mainstream society and can also be adopted by speakers themselves. Such ideologies are usually linked to the presumed lack of economic value of the language, which leads speakers to question its utility and even its status as a selfstanding language. These kinds of ideologies are evident in self-destroying stereotypes such as 'it is only a dialect, it cannot be written', etc. This is often the case for variants that are heavily influenced by the dominant language, which are therefore considered 'corrupt' and 'mixed', lacking 'purity', 'authenticity', and/or 'legitimacy'. Communities may also experience internal political struggles regarding language ownership, local language policy, and language choices; for example, what the future language of the community should be, and if there is any value in keeping or restoring the heritage tongue.

A frequent phenomenon in communities experiencing language shift is purism, an ideology focused on eliminating any features coming from the colonial language. Purism can become an extremely negative force in language maintenance, since purists, who are often people with a powerful status in the community (for example teachers), propose to eliminate any feature coming from the national language. This often hinders the use and development of the local tongue in the way that it is commonly spoken, increasing linguistic insecurity and favoring language shift. For example, both younger and older speakers can be reproached or stigmatized for their way of speaking, depending on the situation and the policy that local purists try to enforce. Yet purism can be turned into a positive force in revitalization programs, depending on specific local conditions. This seems to be the case with the Maya rappers in Yucatan, who have recovered the hach, or 'real Maya', due to its presumed wider repertoire and 'authenticity'. The best recommendation is to avoid favoring any variety or register of a language and to promote community members' acceptance of different contact varieties so that they can contribute to the richness and ecology of the language. 


\section{Exiled, Dispersed, or Resettled Communities}

Some ancestral communities were forcibly exiled or dispersed for historical reasons; some have been completely exterminated due to invasion and aggressive colonization. This happened to the Taino during the Spanish invasion of Cuba in the sixteenth century, and in Tasmania, where the last person solely of Tasmanian descent died in 1905. In cases of almost total genocide, the few survivors that speak the ancestral tongue are the so-called last speakers of a language. Examples are found in many parts of the world, including the native groups of Australia, the USA, Salvador, Chile, Argentina, and Uruguay. Some of those groups are survivors of genocide, as in the case of Nawat/Pipil speakers in Salvador. After the genocide of 1932 they were relocated to other areas of the country, and the traumatizing experience resulted in language loss and forced change of identity. However, even in such dramatic historical circumstances, speakers of Pipil have been identified among the oldest generation, which permitted the launch of revitalization activities. In such cases, however, awakening a language must be closely linked to dealing with historical and personal trauma as well as social healing. For example, in the case of the Pipil it was common to deny speaking the heritage tongue to avoid being killed.

Yet bringing back the ancestral language is often a powerful source of healing and empowerment. One such example is the Diné/Navajo in the USA, for whom language cultivation in schools has become crucial to the recovery of the language. Another case is that of Lemko communities in Poland. Lemko speakers were exiled from their ancestral territories in the Carpathian Mountains almost overnight during the Operation Vistula of 1947. Some were sent to Ukraine, but most of them were resettled to the western region of Poland and the post-German territories, whereas others were confined to postwar concentration camps where the death toll was dramatically high. They were purposefully settled among Polish speakers to foster their linguistic and cultural assimilation. Only a few managed to return to the ancestral region: their houses and lands were occupied and they had to purchase land in their own home territory. They now are a minority in an increasingly Polish-speaking area, which, along with political pressures, has made language maintenance very difficult. Those who stayed in the new lands in the western part of the country experienced even more challenges due to dispersion and severing bonds with their homeland, which was a fundamental part of Lemko identity.

Similar situations have been experienced by many groups of Native American nations, allocated to reservations that were often away from ancestral land and divided among several locations assigned by the US government. Such resettled or dispersed communities are particularly 
exposed to language loss due to the severing of links between an ancestral tongue and ancestral land, which has a number of devastating consequences. Such groups and communities present continua of language maintenance, with different types of speakers who range from monolinguals in the heritage tongue, to bilinguals and monolingual speakers of the imposed language. In such communities there is also a common type of survivor who does not speak the heritage language; in these cases revitalization efforts would have to be based on reviving the language (the most famous case is Hebrew).

\section{Diaspora and Migrant Communities}

Forcibly resettled and dispersed communities are in many ways similar to diasporas of immigrant communities living in urban or other areas (e.g. Veneto in Chipilo, Mexico, or Mennonites in Latin America). These also include the Rom (also called Gypsies), who speak Romani and live in several parts of the world. They are often openly discriminated against by both mainstream society as well as the state, and not officially recognized (France, Colombia, Mexico, Poland, etc.). A common scenario in diasporic groups is language loss within one or two generations, due to the lack of opportunities to use the ancestral language outside of the home. However, at least some of these communities keep their languages as secret codes, which is also a form of 'spontaneous revitalization', meaning an unplanned form of revitalization, that does not have an 'external' agent instigating or accompanying it. In these cases, groups maintain their language as a form of 'in group' communication, as in Romani. These types of communities are remarkably diverse. Some keep strong ties with their homeland (e.g. Mexican Indigenous communities in the USA or Polish communities in the USA and the United Kingdom). Some retain their languages, as is often the case of the Chinese diaspora, and some keep the language partially or create new varieties. The latter includes the para-Romani varieties within the Rom diaspora in Europe, such as the so called Caló in Spain. Linguistic rights of such communities are not recognized by states and therefore they usually do not appear in any censuses.

Different patterns of mobility are associated with diverse types of exodus. These range from permanent migrants (e.g. several Mexican Indigenous groups in the USA or the Turkish population in Germany or the Netherlands) to temporary migrants. An ethnic group can also exhibit mixed patterns and strategies of migration that change over time and in response to political or economic circumstances. Examples include several groups in the USA or the Central American population who relocate to Mexico but then return to their homeland periodically or at least 
occasionally. In this case, due to the sociolinguistic environment and the languages to which they are exposed, the diaspora situation often leads to reduced repertories in the heritage language. It also results in the creation of neo-speakers of neo-urban varieties, and 'receptive' speakers, who can understand but do not speak the language, e.g. children.

Another term that has been proposed with regard to persons who grew up listening to the heritage language but did not become active speakers is 'latent' speaker. ${ }^{2}$ There are also 'rememberers' of dormant languages, and several types of bilinguals (e.g. incipient to almost coordinate bilinguals, that is, speakers who master the two languages almost perfectly and are able to separate them). They continuously face the colonial heritage as it manifests in many forms of discrimination, economic and social disadvantage, as well as covert, and often open, racism. Within the great diversity of migrants, we can also identify 'voluntarily assimilating' speakers who want to abandon their heritage languages as soon as possible to integrate into mainstream society. However we also find groups of speakers who, on the contrary, reaffirm and even empower themselves as immigrants in countries like the USA. This is the case of the Maya of Yucatan, who form a vigorous enclave in the San Francisco bay area, with around fifteen thousand speakers.

\section{Communities of Practice and Learning}

'Communities of practice' ${ }^{3}$ and 'communities of learning' comprise a further category of community. They are a newly described type of group, which deliberately develops social revitalization networks. In the area of language maintenance and revitalization the focus of these groups is on collective efforts to enhance mutual learning and communication, and mobilize available resources. A central goal of such initiatives is to design and carry out specific activities that can positively influence existing practices and situations. Such communities include individuals from different fields who are united in their goal to stop and reverse language shift. Most notably, but not exclusively, these include language activists, linguists, and anthropologists. They may create partnerships with members of the ancestral community who are interested in language revival, or form multidisciplinary and multiethnic teams who are interested in achieving the same goal: language revitalization. Challenges they face involve finding novel ways to empower

${ }^{2}$ See C. Basham and A. Fathman, 'The latent speaker: Attaining adult fluency in an endangered language', International Journal of Bilingual Education and Bilingualism 11/5 (2008), 577-97.

${ }^{3}$ See https://web.stanford.edu/ eckert/csofp.html 
speakers, creating revitalization methodologies through diverse types of collaborations between several stakeholders and generating external support for revitalization programs. Such groups can also include activists from one or more of the ancestral communities, who are united by the goal of keeping their language alive, despite adverse ideologies, attitudes, and educational policies.

An example of the creation of this type of community is the Language Revitalization, Maintenance and Development Project in Mexico, led by Flores Farfán. This project attempts to improve and develop participants' communicative performances and mastership of different language genres, going beyond language abilities per se, to generate highly proficient professionals, such as actors. By engaging in the production of videos or creative writing, the project aims at reactivating speakers' language competences so that they can become proficient speakers and professionals. For instance, after participating in the project, one of the female participants on this program went on to work in the Indigenous education sector in the Balsas region of Guerrero as a bilingual teacher, where she developed community workshops for relearning Nahuatl.

The project actively engaged activists and language leaders from around Mexico in practical training on a range of subjects, including: coaching revitalizers, creating language activists' self-documentation with revitalization in mind, script writing, planning and producing their own books, managing illustration programs, and producing local, culturally sensitive educational materials. This resulted in the creation of language games, animation videos, and books, which are disseminated to children during community workshops led by language leaders (for more details see Capsule 16.6). Also in Mexico, John Sullivan and Justyna Olko carried out a series of interdialectal encounters for the speakers of Nahuatl as well as participatory workshops for reading historical texts created by the ancestors of modern Nahuas and discussing them in the modern variants of this language (See Capsule 12.1). These initiatives have resulted in the creation of networks of engaged language activists (see Chapter 12). Another similar initiative has been the Engaged Humanities project aimed at extensive capacity building and connecting engaged scholars and language revitalization activities all over the world (see Capsule 12.2).

This discussion of course does not cover all possible scenarios. There might also be communities who are only interested in a very reduced use of their languages, often described as symbolic or postvernacular use. In such cases, the active presence of the heritage tongue can be limited to greeting formulas, selected culturally relevant terms, or songs. There are also such communities that do not want to use or revitalize their traditional language at all and it is only linguists who are interested in doing so. 


\section{Speakers of Heritage Languages}

It is very important to emphasize that language communities are not abstract entities. They are composed of many different kinds of speakers of endangered/minority/heritage tongues and, very often, include individuals who no longer speak them. In much the same way as an awareness of diverse community types is important in processes of language shift and language revitalization, the role of distinct kinds of language users is also key. Even in communities where the language is still spoken by the majority, it is not uncommon to find families in which the grandparent and parent generations are fully proficient in the heritage language, whereas the children have different levels of proficiency.

For example, teenagers may speak the language with varying levels of proficiency, their younger siblings may understand the language but not speak it themselves, whereas the youngest siblings may neither speak nor understand the heritage language, having shifted to the dominant or national one. In contexts where language transmission has been broken in this way, scholars have identified 'semi-speakers', 'rusty speakers', 'receptive', or 'passive' speakers 'terminal speakers', 'latent speakers', or 'rememberers', 'pseudo-/quasi-speakers', etc. In revitalization efforts, however, 'labeling' individual speakers can be counterproductive and even discouraging or harmful for people struggling to speak or learn their heritage language. Speakers who struggle to develop their language skills do not want to be categorized by scholars implying their 'incomplete' knowledge and use of a heritage language. In addition, such 'labeling' does not reflect the potential they have for developing their language competence and use. Therefore, any such classifications should be treated with extreme caution; their utility is limited to an assessment of the challenges facing a given revitalization project and they should not stigmatize speakers.

The exact profile of speakers will vary from community to community, despite some common characteristics. Similar to the profile of communities, these categories should be viewed as having blurred and dynamic boundaries, existing within broad continua of language proficiency. Here we give an example of a general typology of speakers that is based on the different communities we have worked with in Mexico, especially Nahuas. However the typology can be applied, to a certain extent, to other communities, depending on their unique situation.

1. Selected speakers with a very high Nahuatl proficiency are often the 'top owners' of the language. They are specialized in specific types of discourses, such as bride or rain petitions or ritual activities conducted through chants by healers or enchanters. Members of conservative, 
traditional communities pay high respect to this type of speakers and hire them on special occasions. Recovering such genres of speech in communities that have lost them might be one of the ways of revitalizing the language, giving it prestige and expanding its linguistic repertoires. In these cases specific revitalizing methodologies can be developed.

2. Fully proficient speakers - often scholars, students, writers, or activists - who are conscious users of the language and who reveal a huge capacity in the language in any domain; some of them hold purist attitudes toward the language and avoid loanwords and code mixing. They are usually bilingual with different degrees of influence from their mother tongue in their Spanish. Some use an almost 'standard' Spanish, whereas others clearly exhibit at least some influence from Nahuatl.

3. Quasi/almost monolingual speakers whose proficiency in Nahuatl is very high and who have limited contact with the Spanish-speaking mainstream society. These speakers are usually elders and often females, although they also include adults, young speakers, and even children who only start learning Spanish when they begin attending school. Empowering these speakers is an important strategy for revitalization. This can be achieved, for example, by legitimizing them at the school level and reestablishing intergenerational language bonds that might be weak.

4. Fluent bilingual speakers from traditional communities with unbroken transmission who either still use the language in their home community or who have migrated but continue speaking whenever they visit the community and sometimes even when they are abroad. The use of language and adaptation skills in different domains varies, but generally their proficiency is very high. There is even a trend to acquire a third language, such as English as in the case of Maya Yucatec speakers in the San Francisco area in the USA. This type of migrant shows that migration is not always a displacing feature, but can in fact be a revitalizing force due to the strong identity ties speakers develop while living far away from their homeland.

Depending on the region and community of origin, some of these speakers resort to heavy code mixing in certain situations. For example, this is sometimes seen in teenagers or young adults who learned the language when growing up and use it at home and among their peers but who received no school instruction in it. Sometimes it is impossible to differentiate this category of speakers from less fluent speakers. Furthermore, their proficiency may vary depending on the domain or the topic of conversation. 
5. Bilingual speakers who are socialized in the heritage language in increasingly bilingual homes, sometimes learning it from their grandparents or other family members. Their use of the language is limited to basic domains and their vocabulary and use of grammatical structures is reduced; some of them purposefully omit loanwords and code mixing, especially in the presence of teachers or researchers. Spontaneous speaking on a wide variety of topics requires considerable efforts on their part. As with other categories, the distinction between this type of speakers and other kinds of asymmetrical bilingual speakers is fluid. Such individuals' proficiency exists on a continuum. Some of them learned the language at a later age, when they were teenagers or young adults. This may have been due to pressures from the community and their expected participation in domains such as commercial or ritual activities. Alternatively, they may have been motivated to learn the language for personal reasons. Speakers who are self-motivated to learn the ancestral tongue later in life often become committed teachers and can be important agents in revitalization efforts.

6. Insecure or 'dormant' speakers who learned the language as children but have not been using it regularly or for an extended period of time; some use it in very limited domains and on specific occasions. These language users are typically members of communities with broken language transmission and/or migrants with a recessive use of the heritage tongue. This broad category includes speakers who only use the language under pressure or for specific purposes (for example in commercial exchanges). We can also find second language learners who try to recover their mother tongue or, on the contrary, individuals who decided to stop using it. In general, their speech is characterized by heavy borrowing, code mixing, and code switching. They often exhibit difficulty and insecurity in expressing themselves. Such speakers are frequently ashamed of their reduced language skills, a possible prelude to language loss if revitalization actions are not taken.

7. 'Receptive' or 'latent' speakers whose competence is restricted to understanding the language to differing degrees. In specific communicative situations they may function adequately with no difficulty in understanding. These situations may include farming or other work places, family reunions, (often religious) festivities, and the market place. Depending on the degree of contact with other more fluent speakers, this type of speaker has different degrees of comprehension of the endangered language. Activating such speakers can become an important part of revitalization efforts, helping them move from 'listeners' to 'speakers', who then may develop a high level of fluency in the language. 
8. New speakers who are already fluent in the colonial/dominant/national language but attempt to recover their mother tongue and use it as a second or even third language. In the case of Nahuatl, this type of speaker has varying degrees of Spanish proficiency. In turn, this can have varying degrees of impact on their Nahuatl use, affecting all levels of the language (for example pronunciation, morpho-syntax). New speakers are very important, often essential, for language revitalization projects. As with other continua, this group of speakers also includes a diversity of individuals, encompassing people who are 'symbolic' speakers, that is, Spanish monolinguals with no real intention of recovering the language, who use only a few formulaic words and phrases for political reasons (for example being identified as an ingroup member). Such symbolic speakers are in contrast to new speakers who are really committed to recovering their mother tongue.

\section{Conclusions}

As we have shown, language revitalization efforts take place across very broad and diverse situations and communities, and involve many types of speakers. All endangered languages and their speakers are in a permanent state of flux, existing in complex language ecologies where heterogeneity is the norm. This should be taken into account and respected; all revitalization projects must understand and deal with such complexity in order to design and develop well-informed and efficient strategies to reverse language shift. In addition to pointing out the diversity of situations, linguistic variants, speakers, proficiencies, attitudes, motivations, and goals that exist, we also want to warn against applying biological metaphors to the context of language endangerment and revitalization.

Such metaphors can be harmful when we consider, for example, that in the biological sciences, revitalizing a species can be done through intervention and even genetic reconstruction. However, when working with people and their languages, we should focus on the agency of human beings as a fundamental aspect of recovering endangered languages. For this reason, when considering any revitalization project it is important to account for the cultural strategies and practices of communities and speakers, as well as the different goals and outcomes they aspire to. By comparing distinct kinds of communities and speakers, we can conceive (re)vitalization as a continuum ranging from dormant languages to highly vital and viable languages that are, nevertheless, still threatened.

Therefore, the range of possible, and often complementary, efforts made by different actors, including academics, can be envisioned as attempts aimed at (re)vitalizing, (re)covering, (re)claiming, (re)evaluating, (re)versing, (re)creating, and (re)activating endangered languages. The many scenarios 
and kinds of 'communities' and 'speakers' we have outlined in this chapter can hopefully serve as useful starting points for developing additional recommendations and points of reflection for future revitalization projects, which are focused on good practices and sensitivity toward local diversity. One of several possible practical goals could be, for example, to engage with many different kinds of speakers in joint and collaborative revitalization efforts, creating a sense of 'community' by reestablishing and strengthening language bonds and identities between different generations and diverse types of speakers.

\section{FURTHER READING}

Fishman, J. (1991). Reversing Language Shift. Clevedon: Multilingual Matters. McCarty, T. L. (2018). Community-based language planning. Perspectives from indigenous language revitalization. In L. Hinton, L. Huss, and G. Roche, eds., The Routledge Handbook of Language Revitalization. New York and London: Routledge, pp. 22-35.

Mithun, M. (1998). The significance of diversity in language endangerment and preservation. In L. Grenoble and L. Whaley, eds., Endangered Languages. Language Loss and Community Response. Cambridge: Cambridge University Press, pp. 163-91 O'Regan, H. (2009). A language to call my own. In A. M. Goodfellow, ed., Speaking of Endangered Languages. Cambridge: Cambridge Scholars, pp. 184-98.

\subsection{The Community of Wymysoü}

\section{Tymoteusz Król}

Wymysoü (Wilamowice) was founded in the thirteenth century by colonists of Germanic origin. It started as a small village, then in 1818 it became a town with around 2,000 inhabitants. The number of people in Wilamowice did not increase as rapidly as in the surrounding villages because a relatively large proportion of the population were students, who left to study in other cities and then remained there. Many of them were Catholic priests, who were sent to parishes far from their hometown. Moreover, Vilamovian merchants used to travel all over Europe and stay in big cities, where they had commercial interests. The biggest colony of Vilamovians was in Vienna, where there were a couple of hundred, and in Cracow, where there were also about a hundred. The Wymysiöeryś language has never been spoken outside Wilamowice and the two colonies of Vienna and Cracow. Today in Vienna there are some people who speak Wymysiöeryś, but those in Cracow became assimilated into Polish culture.

The community structure of Wymysoü before World War II was complex. There were five social strata: intelligentsia, big farmers, merchants, small farmers, and servants. In the nineteenth century there were also weavers, who used to have their own way of using the language. Marrying people outside of Wilamowice or even outside of one's own social stratum was not favored, but merchants used to marry Jews and people from Vienna. Servants in the town were often Poles and Germans 
from surrounding villages, and they married Vilamovian servants. There were also strong Jewish and Rom communities in the area.

The occupation of Poland by the Nazis and the following period under communism destroyed this multiculturalism. Those Jews and Rom who could not emigrate to escape the Holocaust were murdered in concentration camps. After World War II, the Vilamovians were sent to postwar concentration camps in Russia and Poland. The Polish communist authorities issued a decree forbidding people from speaking Wymysiöeryś and wearing Vilamovian folk dress. They also expelled the Vilamovians from their houses for thirteen years. At that time their Polish neighbors developed highly negative attitudes toward Vilamovians. The oldest generation remained Wymysiöeryś, but the younger one used to inform their children that they should be Poles, and not reveal their Wymysiöeryś identity. Many people married Poles because this provided protection against persecution. This was also a response to negative ideologies, which said that Vilamovians should mix their blood because, due to their previous endogamy, they were mentally handicapped. Even Vilamovians said that it would be better if their language and identity died.

But at the beginning of the twenty-first century the young generation 'woke up' and started discovering the past of their parents and grandparents and developing their own identity. As a result, the language and other elements of Vilamovian culture started to become present in public life again. Now there are plenty of Wymysiöeryś/Vilamovian identities: people feel Vilamovian and Polish, Vilamovian and Austrian, or just Vilamovian. Some people say that the young people are doing a great job in revitalizing the language and local identity. But many local activists and politicians say it is dangerous to bring the old Vilamovian identity back - an identity that is not Polish. They do not understand that times have changed and that the young generation is not bound by the old negative attitudes. The young Vilamovians are creating their own identity by selecting parts of the old Vilamovian culture and taking inspiration from other cultures - thanks to visits to such places as Nahua communities in Tlaxcala and the Isle of Man. They are building a new Wymysiöeryś identity and a new speaker community, which are not the same as the one at the beginning of twentieth century. And they have a right to do it, even if they work against the Polish nationalist mainstream, or even against some of the norms and expectations represented and expressed by the older generations.

\subsection{What Is Community? Perspectives from the Mixtec Diaspora in California}

\section{Griselda Reyes Basurto, Carmen Hernández Martínez, and Eric W. Campbell}

If we define 'community' broadly as a group of people who share certain linguistic, cultural, and/or social practices, then the notion of community is fluid and 
dynamic, and the relationship between people and communities may be many to many rather than one to one. In language documentation and revitalization, community has traditionally referred to a village or set of villages that share a common language or set of language varieties. However, especially in the digital age, even this narrower notion of community is not bound to physical topography, and in the postcolonial age, communities may find themselves distributed over large and discontinuous spaces and media. Here we briefly consider the notion of community in the context of the Mixtec Indigena diaspora in California, which may serve as an example or point of comparison for other diasporic communities around the world. We use the term Indigena to refer to Indigenous peoples of California whose traditional communities are located in Mexico or Central America, instead of the broader term Indigenous, which could also include Indigenous peoples with longer histories in present-day California.

Traditional Mixtec communities in Mexico are numerous and situated in western Oaxaca, eastern Guerrero, and southern Puebla states. The political, social, economic, and environmental effects of colonialism have led to large-scale emigration of Mixtec and other Indígena peoples to other parts of Mexico in the 1930s and to the United States in the 1940s-1960s with the Bracero Program, increasing in the 1980s. In California, diverse Indígena populations have settled in and around San Diego, Los Angeles, Ventura County, Santa Maria, Salinas, Fresno-Madera, and other locales. The settlement of large numbers of people from Mesoamerica has led to the emergence of a new, diffuse, and multiethnic community that Michael Kearney termed Oaxacalifornia.

Indígena workers are now an integral part of California's enormous agricultural economy. However inequality and discrimination often migrate along with the people who suffer these forms of injustice; Indígena workers may be marginalized as relatively recent arrivals in the USA on the one hand, and then further marginalized and discriminated against within the larger migrant labor force for being Indígena. They are often lumped into 'Mexican' or 'Latino' groups with whom they do not identify, and they are not provided adequate medical, educational, legal, and labor services.

Families are shifting to Spanish in many origin communities in Mexico, and especially in the diaspora. Many youth and children who do speak their native languages feel compelled to abandon them, both because of bullying and discrimination by their peers and due to the dominant society's lack of recognition of their language and culture. The result is that youth have been uprooted and disconnected from communicating in their languages, which threatens the linguistic and cultural continuity of their communities. In response to their economic and social challenges, and the discrimination that they face, Indígena peoples have created binational and local community organizations, such as the Mixteco/Indígena Community Organizing Project of Ventura County, California, to enhance collective efforts and share resources and information.

Ventura County is now home to as many as 20,000 Indígena people, most of whom are Mixtec, and they speak at least fifteen Mixtec varieties, not all of which are mutually intelligible. Each individual has a unique set of language practices that 
may include their Indigenous language, English, and Spanish, depending on how much time they have lived in the USA, the work that they do, and their personal interests. Most people identify with a 'hometown' community in Mexico, but for many, the community they know and experience the most is the diverse Indígena community of Ventura County. As this example illustrates, we should not essentialize or stereotype Indigenous languages and people, for example, by assuming that they only live in far-away traditional homelands. In order to meet everyone's linguistic and social needs, we should recognize that there are diverse and diaspora communities outside of traditional areas and people may belong to multiple communities.

\subsection{An Introspective Analysis of One Year of Revitalization Activities: The Greko Community of Practice}

\section{Maria Olimpia Squillaci}

In this capsule, I shall briefly describe a series of actions recently taken toward the revitalization of Greko, a critically endangered Greek language, spoken in southern Calabria (Italy), which favored the constitution of a community of practice.

The first attempts to revitalize Greko began in the 1960s, when a group of mostly young people started to actively campaign for the safeguarding of this language and its culture. Since then, many associations have been founded, and very many cultural activities and local/regional programs have been implemented with great opportunities for local development. All this has brought about a very significant change in the attitude of the community toward its own language, which moved from being hidden and despised to being a source of pride. However associations have not been able to secure the intergenerational transmission of Greko at home, resulting in a continuous decrease in the number of speakers. Furthermore, in the last ten to fifteen years, there has also been a progressive reduction of activities in support of the language.

For this reason, five years ago I launched a new summer school 'To Ddomadi Greko - the Greko week', thanks to the support of the old but still-active association Jalò tu Vua. In my mind the Ddomadi Greko had to be a one-week injection of language, enthusiasm, and stimuli to shake up once again the community's interest for Greko and to draw attention to its critically endangered status. My ambition was to (re-)create a strong connection between local people, especially the young generation, and their heritage language, allowing them to discover the richness of their own native place. The school included four hours of language teaching every day, a one-hour cultural seminar, and one afternoon excursion. The result was extremely positive, to the extent that two years ago, we gathered together a group of young participants, potentially interested in engaging with language revitalization.

The first step was the creation of a WhatsApp chat to practice Greko every day, favoring in particular the use of voice messages. Whoever joined the group had to use the Greko words that they knew, even inserting them in an Italian phrase, and if there was a mistake, someone had to correct it and give a grammatical explanation 
for it. A very useful tool that really facilitated texting in Greko was Grekopedia, the smartphone application with an Italian-Greko Greko-Italian dictionary that my father and I had launched a year before. However, to avoid the creation of a dead chat, we all decided to undertaking several tasks, the first of which was the setting up of the Facebook page 'To Ddomadi Greko' (following success using social media to promote other languages - see Chapter 17), which would cover grammatical topics, traditional songs, stories, memes, and gifs in Greko (on the model of the Colectivo Tzunhejekat facebook page for Nawat).

As trivial as it might seem, this process immediately got great results since it gave visibility to the group, encouraging other people to join in, including Calabrian emigrants and foreigners. Most importantly, however, the management of the page required the group members to practice Greko every day, to find or to create Greko material to post and, crucially, to communicate with the rest of the group. This continuous exchange enormously accelerated their learning process and fostered great collaboration within the group. Tandem activities too, even carried out on Skype for those living outside of Calabria, facilitated team building, a crucial and sensitive part of the revitalization program. To this end, we also used theater as a key tool to quickly improve language skills and a great space for teamwork. The most important results were not the activities per se, but the fact that the management and supervision of them was fully carried out in Greko among people living in different parts of Italy and Europe. In less than a year we managed to build up a community of practice whose main goal was the revitalization of Greko. ${ }^{4}$ Crucially all this was actively supported by many older Greko speakers who constantly joined us in our events and we would regulalrly visit them at their place as part of our core activities. The collaboration between the group of new young speakers and the older ones was our strength as it fostered the creation of strong affective bonds among the young members of the group and across generations. This became the driving force of our work and also had a huge impact in terms of language learning, since younger people have progressively stopped learning new words and grammatical rules from books and began learning them by transmission, by living the language in this new kind of community.

${ }^{4}$ I soon realized that we also had to give Greko an economic value, to make all our efforts sustainable over time. For this reason, we launched the crowdfunding campaign 'If you speak me, I live - adopt Greko', in order to secure funds for revitalizers to teach and work for the language and to do so by remaining in Calabria, which is per se a big challenge, Calabria being one of the poorest regions in Italy. At present, establishing a link between people's knowledge of Greko and job opportunities in Calabria is our top priority as it might bring to substantial changes in the long run. 